Sex Roles, Vol. 3, No. 5, 1977

Brief Report

\title{
The Development of Parental Preferences in the First Two Years of Life ${ }^{1}$
}

\author{
Michael E. Lamb ${ }^{2}$ \\ University of Michigan
}

This study was conducted to explore sex of parent by sex of child interactions in the development of parent-infant attachments in the first two years of life. Such investigations seem especially necessary in view of the common belief that sex-role learning primarily occurs in the process of early family-child interactions (see Lamb, 1976c). Unlike the few previous investigations in which fatherand mother-infant relations were compared, the data were derived from lengthy observations of family triads in the unstructured home setting.

Pilot laboratory research conducted by Lewis, Weinraub, and Ban (1972) and Lamb (1976b) indicated that by 2 years of age boys tend to prefer their fathers while girls prefer their mothers. In neither study were individual developmental profiles considered, nor was it clear whether infants who showed a preference for one parent on one measure showed a similar preference on the other measures. The present study was designed to remedy these deficiencies. In addition, the frequency of parental vocalization to the children was recorded; this served as an index of parental interactive participation. It was predicted that the sons' preferences for their fathers would be paralleled by greater paternal involvement with sons than with daughters.

The subjects were participants in two overlapping longitudinal investigations. Fourteen infants were observed at $7,8,12,13,15,18,21$, and 24 months of age; six others were observed at $7,8,12$, and 13 months; and six were observed at $15,18,21$, and 24 months. All came from lower- to upper-middle-class families, in which traditional parental roles prevailed.

${ }^{1}$ This research was supported by two grants from the Ecology of Human Development Program of the Foundation for Child Development.

${ }^{2}$ All correspondence and requests for an Extended Report should be addressed to Michael E. Lamb, Department of Psychology, University of Michigan, Ann Arbor, Michigan 48104. 
Observations took place at home and each lasted about 90 minutes. An observer dictated a narrative account of the infant's interaction with mother, father, and another investigator (the Visitor). The analyses are based on the frequency of occurrence of five attachment behaviors: proximity, touching, approaching, asking to be picked up, and fussing. The behavioral definitions and coding procedures were described by Lamb (1976a), who has reported previous analyses of these data (Lamb, 1977a, 1977b). Reliability in the observation and coding of these behaviors was consistently better than .75. Infants were considered to have shown a preference for one person over another only if four or five of the measures were directed more often to that person than to the other in a pair of adjacent visits. Inferences about developmental changes are thus based on four age periods ( $7-8,12-13,15-18$, and 21-24 months).

At 7 to 8 months, 12 of the babies ( 6 of the 10 boys, 6 of the 10 girls) showed clear preferences for the parents over the visitor, thus demonstrating that they had entered the third stage in the development of attachment (Bowlby, 1969). Three of these babies preferred their mothers over their fathers, while one showed a preference for his father. The majority showed no parental preference. By 12 to 13 months, 18 infants had entered Stage III, and the majority now showed preferences for one parent over the other. Seven ( 5 boys, 2 girls) preferred their fathers, while five ( 3 girls, 2 boys) preferred their mothers. During the second year, an increasing proportion of the infants showed definite parental preferences. At 15 to 18 months, nine (6 of the 9 boys, 3 of the 11 girls) preferred their fathers, and 4 girls preferred their mothers. In the final semester, the figures were 9 ( 6 boys, 3 girls) and 6 ( 5 girls, 1 boy), respectively. Considering the last four visits together, 8 of the 9 boys $(p<.02)$ showed preferences for their fathers, while 5 of the 6 children preferring their mothers were girls $(p<.10)$.

The pattern of preferences at 7 to 8 months was not significantly correlated with the pattern at 12 to 13 months. A similar lack of stability was indicated by a correlation of the patterns at 12 to 13 and 15 to 18 months. During the second year, however, extensive stability was evident; the correlation was significant both for the whole sample $(\rho=.54 ; p<.02)$ and for the 14 infants observed in both the first and second years $(\rho=.63 ; p<.05)$.

In the first year, neither parent vocalized to the infant more often than the other, and there no sex differences. From 15 months, however, fathers spoke to the infants more than mothers $(\bar{X} \mathrm{f}=1.66$ per minute; $\bar{X} \mathrm{~m}=1.24 ; p<.05)$, and boys were addressed more than girls $(\bar{X} \mathrm{~b}=1.75 ; \bar{X} \mathrm{~g}=1.2 ; p<.001)$. Fathers were twice as interactive with sons as with daughters, and twice as interactive with the sons as the mothers $(p<.001)$. Both parents addressed daughters equally often.

These results show that there are impressive sex of child $X$ sex of parent interactions apparent in the behavior of both parents and children. These patterns 
are evident from the beginning of the second year, which is when stable preferences emerge. Fathers appear to make themselves particularly salient to sons, and this presumably fosters the development of close father-son relationships.

There is reason to believe that these relationships may be important in the development of sex roles in young boys. Studies of boys raised in father-absent families indicate that sons separated from fathers in infancy or early childhood are most seriously affected, suffering deficiencies in sex-role adoption and achievement motivation (cf. Lamb, 1976c). Blanchard and Biller (1971) found that boys whose fathers interacted little with them were affected in the same way as father-absent peers. Meanwhile, the absence of especially close motherdaughter bonds is consistent with evidence that pressures toward sex-role adoption begin earlier, and with greater intensity, in boys (cf. Lamb, 1976c). The results imply that students of sex-role adoption must pay more attention to younger ages and to the potential importance of the father-infant relationship.

\section{REFERENCES}

Blanchard, R. W., \& Biller, H. B. Father availability and academic performance among third grade boys. Developmental Psychology, 1971, 4, 301-305.

Bowlby, J. Attachment and loss. Vol. 1. Attachment. New York: Basic Books, 1969.

Lamb, M. E. Interactions between eight-month-old children and their fathers and mothers. In M. E. Lamb (Ed.), The role of the father in child development. New York: Wiley, 1976. (a)

Lamb, M. E. Interactions between two-year-olds and their mothers and fathers. Psychological Reports, 1976, 38, 447-450. (b)

Lamb, M. E. The role of the father: An overview. In M. E. Lamb (Ed.), The role of the father in child development. New York: Wiley, 1976. (c)

Lamb, M. E. Father-infant and mother-infant interaction in the first year of life. Child Development, 1977, 48, 167-181. (a)

Lamb, M. E. The development of mother-infant and father-infant attachment in the second year of life. Developmental Psy chology, 1977, 13, in press. (b)

Lewis, M., Weinraub, M., \& Ban, P. Mothers and fathers, girls and boys: Attachment behavior in the first two years of life. Unpublished manuscript, Educational Testing Service, 1972. 